\title{
The Role of Inhibition in Learning
}

\author{
Justin C. Hulbert and Michael C. Anderson \\ University of St. Andrews, U.K.
}

A retentive memory may be a good thing, but the ability to forget is the true token of greatness.

Elbert Hubbard

None of us wish for a poor memory. Knowledge and skill are precious commodities we aim to amass, preserve, and disseminate. The pangs of frustration felt when we forget a colleague's name, an important appointment, or a friend's birthday motivate the desire to have all of our memories constantly accessible. Yet, one only needs to skim the fictional case of Funes, the Memorious, by Jorge Luis Borges or the real-life tale of mnemonist Solomon Shereshevskii to appreciate the pain and complications associated with being unable to control which memories spring to mind. Indeed, in everyday life, there are many situations in which remembering is disadvantageous. For instance, simultaneously recalling all the spots in which one has ever parked would be more confusing than helpful in locating the car at the end of the day. In such cases, it is desirable to selectively retrieve only the most current, contextually relevant information (e.g., where one parked today). To the extent that irrelevant details (e.g., the location of yesterday's parking spot) intrude, our goals are undermined. Similarly, intrusive reminding of unpleasant, upsetting, anxietyprovoking, or embarrassing events-like memories of trauma or losscarry the potential to distract us from our current tasks. When confronted with such reminding, we may wish to stop retrieval entirely. In both cases-selective retrieval and stopping retrieval-an inhibitory process that renders unwanted memories less accessible would prove quite adaptive (Anderson, 2003; Bjork, 1989).

Before discussing these two situations in turn, it is worthwhile to describe the view of forgetting we will advance. Forgetting has long been relegated to the backseat in discussions of learning. Classically, forgetting 
was thought to result either from a slow decay caused by disuse or, as Müller and Pilzecker (1900) proposed, as a passive consequence of learning new material that interferes with the old. In contrast, we adopt a functional view of forgetting. As outlined by Anderson (2003), we argue that forgetting is largely a consequence not of learning, per se, but of the executive control processes recruited to resolve response competition arising during memory retrieval. In this chapter, we summarize the ways in which the forgetting associated with one important facet of executive controlinhibition-actually facilitates learning.

\section{Inhibition in selective retrieval}

Memory retrieval is not always as simple as following a straight path from a reminder to a target. More often than not, a given retrieval cue is related to many memories, only a subset of which are useful in a given situation. A rich body of research demonstrates a strong relationship between the number of memory competitors associated with a cue and the difficultly in successfully retrieving a particular target memory (e.g., Anderson, 1974; Anderson \& Neely, 1996; McGeoch, 1942; Postman, 1971). The problem is compounded when we must overcome a prepotent, yet inappropriate, memory trace in favor of a weaker, relevant one. Consider mistakenly dialing a friend's outdated telephone number right after she moved or searching for keys in the end table where we normally keep them rather than in our pants where we left them the night before.

The intrusion of inappropriate memories is distracting and often deleterious to our goals. Conceptually, one should be able to resolve the resultant interference through a combination of boosting the target memory's signal and decrementing the strength of competing memories. To illustrate, repeatedly dialing a friend's current telephone number would elevate the accessibility of that number, while attenuating our ability to access to the older one, even if asked. Decades of empirical research have highlighted the ways in which we can facilitate target memory retrieval (Thorndike, 1932); work in our lab, however, has primarily focused on the latter method of satisfying our mnemonic goals.

Should an unwanted memory impede retrieval of a target trace, we claim that inhibitory control mechanisms are recruited to override or suppress the intrusive memory in favor of the more contextually appropriate response. Such a mechanism would prove especially advantageous if, as a consequence of retrieving the target memory, it reduced the likelihood that the competitor would intrude over the long-term. Hence, the very act of remembering should cause lasting forgetting. If so, when confronted with a similar situation in the future, we could easily retrieve the relevant 
information, unencumbered by intrusions from outmoded or erroneous knowledge.

Research from our lab and others has shown that selectively retrieving target traces does suppress competing memories. In the retrieval practice procedure designed to investigate this phenomenon (Anderson, Bjork, \& Bjork, 1994), participants typically study lists of category-exemplar pairs (e.g., FRUITS-BANANA, DRINKS-SCOTCH, and FRUITS-ORANGE) and subsequently practice retrieving half of the exemplars from half of the categories multiple times, given category and wordstem cues (e.g., FRUITS-OR___. Following a 20-min delay, participants are asked to recall all of the previously studied exemplars. Not surprisingly, retrieving some items (e.g., ORANGE) during retrieval practice yields improved recall for those items compared to baseline items from unpracticed categories (e.g., SCOTCH). More revealing is the finding that retrieval practice impairs recall for unpracticed items from practiced categories (e.g., BANANA) relative to baseline items. This finding, referred to as retrieval-induced forgetting (RIF), has since been demonstrated using a wide variety of stimuli (for reviews, see Anderson, 2003; Levy \& Anderson, 2002), including ambiguous words (Shivde \& Anderson, 2001), visuospatial objects (Ciranni \& Shimamura, 1999), unusual actions (Koutstaal, Schacter, Johnson, Angell, \& Gross, 1998), personality traits (Koutstaal, Schacter, Johnson, \& Galluccio, 1999; Macrae \& MacLeod, 1999b), eyewitness memories (MacLeod, 2002; Shaw, Bjork, \& Handal, 1995), and autobiographical memories (Barnier, Hung, \& Conway, 2004).

Although consistent with the notion that inhibitory control is recruited to overcome interference during retrieval practice, the basic findings of RIF could also be explained by several noninhibitory mechanisms (for a review, see Anderson et al., 1994). For instance, the strengthened, practiced items may come to intrude so pervasively during later memory tests that participants' attempts to retrieve the unpracticed responses are effectively occluded, a circumstance referred to as associative blocking. If forgetting is produced solely by strengthening practiced items, then doing so through extra exposure without actual retrieval practice should be just as effective in reducing the final recall of unpracticed competitors. Contrary to a noninhibitory account, such conditions fail to produce RIF, despite facilitating the practiced items to the same degree as does retrieval practice (Anderson \& Bell, 2001; Anderson, Bjork, \& Bjork, 2000; Bäuml, 1996, 1997, 2002; Ciranni \& Shimamura, 1999; Shivde \& Anderson, 2001). Thus, RIF appears to be specifically induced by retrieval and dissociable from the degree to which practiced items are strengthened.

A second, noninhibitory account called associative unlearning might frame the basic findings of RIF in terms of damage exacted upon the 
associative bond linking the category cue and the unpracticed exemplar. Accordingly, retrieval practice reduces the viability of the category label to serve as an effective cue for the unpracticed item-that is, it merely damages one pathway to the competing memory. Only an inhibitory account in which the competing memories are actively suppressed, though, accurately predicts that RIF is independent of the cue used during retrieval practice and should generalize to novel cues (Anderson \& Spellman, 1995). For example, after retrieving FRUIT-ORANGE from memory, later recall of BANANA should be impaired regardless of whether it is cued by the originally studied category (FRUITS-) or by a novel, independent retrieval cue (e.g., MONKEY-B). Cue-independent forgetting of this sort has since been demonstrated numerous times (e.g., Anderson \& Bell, 2001; Anderson et al., 2000; Anderson \& Spellman, 1995; Aslan, Bäuml, \& Pastotter, 2007; Camp, Pecher, \& Schmidt, 2005; Levy, McVeigh, Marful, \& Anderson, 2007; MacLeod \& Saunders, 2005; Saunders \& MacLeod, 2006), including in a classic retroactive interference paradigm (Hulbert \& Anderson, In Preparation) and in another, related method referred to as part-set cuing (Aslan, Bäuml, \& Grundgeiger, 2007).

The real-world implications of RIF are brought into focus when one considers circumstances that demand accurate and complete fact retrieval, such as eyewitness testimony and academic examination. As Shaw et al. (1995) and MacLeod (2002) have independently shown, prompts to recall specific details of mock crime scenes impair the ability to recall related but previously undiscussed particulars, demonstrating anew that retrieving some experiential elements impairs others. Clearly, RIF is a double-edged sword, facilitating the retrievability of practiced items at the expense of related items that, though not germane at the time of practice, could later return to relevance. Likewise, students are commonly presented with an abundance of facts and ideas related to a given topic and tested on specific items. As their knowledge base for a particular topic grows, retrieval of any one fact is slowed in response to the need to resolve competition from an increasing number of memory associations, a finding J.R. Anderson (1974) termed the fan effect. The necessity to expediently retrieve selected facts in a testing situation should, therefore, recruit inhibitory control mechanisms to resolve the amassed interference. Sure enough, Anderson and Bell (2001) generalized RIF to fact retrieval by having participants study propositions such as "The Actor is Looking at the Tulip" and practice only a subset of facts related to a topic. As a result, participants were not only rendered less able to recall related, unpracticed facts (e.g., "The Actor is Looking at the Violin") after a delay, but also less likely to recall other learned facts in which the inhibited object participated (e.g., "The Teacher is Lifting the Violin") (see also Gomez-Ariza, Lechuga, Pelegrina, \& Bajo, 2005; Macrae \& MacLeod, 1999a). 
Both academic and research settings abound with circumstances that encourage the selective retrieval of certain facts related to a given topic. Consider professors and experts, who routinely retrieve and present only a subset of their wealth of knowledge. Would selective retrieval affect experts' untapped competence in the same way it influences their students? Though more work is necessary, evidence indicates that specialists manage to preserve their expertise despite the circumstances. In one recent example, Carroll, Campbell-Ratcliffe, Murnane, \& Perfect (2007) asked both first-year psychology students (i.e., novices) and psychology majors (i.e., relative experts) to examine a pair of case studies adapted from an upper-level abnormal psychology textbook. All participants were then repetitively quizzed on some of the information for half of the case studies through a series of questions (with corrective feedback), as though they were preparing for an upcoming exam with a study partner. Final testing on the entirety of the studied material after a 15-min delay revealed that novices were significantly less able to recall unpracticed details from the practiced case study compared to baseline items. Experts, however, experienced no measurable RIF, owing, the authors claimed, to experts' ability to integrate the learned material into existing knowledge schema and reducing the extant amount of competition and consequent forgetting (see also Smith, Adams, \& Schorr, 1978). In fact, Anderson and McCulloch (1999) demonstrated that simply instructing naïve participants to integrate novel information during the initial study phase of a standard RIF paradigm was enough to significantly reduce forgetting on the final test. In a separate study, participants who later claimed to have spontaneously engaged in integrative learning without explicit instruction were also largely shielded from the forgetting effect experienced by nonintegrating participants (Anderson \& Bell, 2001).

Remarkably, even the material over which we command great expertise is rendered susceptible to RIF to the extent that it competes with information not yet well-integrated into our current knowledge structure. Take another real-world example of learning: second-language acquisition. Subsequent to immersion in a foreign language environment, such as a semester abroad, individuals commonly report what is called first-language attrition, a phenomenon characterized by difficulty in retrieving nativelanguage words. In order to simulate this experience, Levy et al. (2007) had native English speakers practice naming objects in a second language they were studying in school: Spanish. The authors reported significant forgetting of English phonological labels after naming objects in Spanish a mere 10 times. In line with prior results regarding expertise, those participants with relatively greater Spanish fluency were subject to less inhibition than participants rated less adept in the foreign language. Thus, inhibition appears to be most heavily recruited during the early stages of second-language 
acquisition, thereby facilitating retrieval of the weaker, foreign language in the face of the otherwise overwhelming dominance of the native vocabulary. This finding is consistent with interference dependence, the finding that retrieval only inhibits related traces to the extent that they pose a considerable threat of interference (Anderson et al., 1994; Shivde \& Anderson, 2001).

In recent years, electrophysiological and functional imaging techniques have converged to help illuminate the neural correlates of inhibition resulting from selective retrieval. Johansson, Aslan, Bäuml, Gabel, and Mecklinger (2006) recorded event-related potentials (ERPs) from participants as they engaged in retrieval practice or were simply given extra study exposures. Electrical activity over the prefrontal region of the brain was modulated by task, revealing a sustained, positive-going augmentation of ERP waveforms bilaterally when participants engaged in selective retrieval. Moreover, activity recorded over this region (specifically, late anterior frontal amplitudes) during selective retrieval—but not during extra study exposure-predicted individual differences in the amount of subsequently observed RIF, accounting for one-third of the variance. These results are in line with the notion that the prefrontal cortex is heavily involved in cognitive control processes, including selective memory retrieval. Converging evidence was provided by Kuhl, Dudukovic, Kahn, and Wagner (2007) who utilized the heightened spatial resolution of functional magnetic resonance imaging (fMRI) to identify brain regions that reflect the level of demand for cognitive control as competition is reduced over the course of retrieval practice. The right ventrolateral prefrontal cortex (VLPFC) exhibited just this property, with the reduction of neural activity from the first to the third retrieval practice attempt predicting forgetting in the subsequent final test. This region has often been implicated in a wide variety of executive control tasks (e.g., Bunge, Ochsner, Desmond, Glover, \& Gabrieli, 2001; Garavan, Ross, Murphy, Roche, \& Stein, 2002; Jonides, Smith, Marshuetz, Koeppe, \& Reuter-Lorenz, 1998; Menon, Adleman, White, Glover, \& Reiss, 2001; Nakahara, Hayashi, Konishi, \& Miyashita, 2002; Shimamura, 2000).

The inverse relationship between brain activity and increased forgetting also held for the anterior cingulate cortex (ACC), a finding that deserves special discussion. As neuroimaging studies of executive control have tied this brain region to the detection of conflict between competing responses (Botvinick, Braver, Barch, Carter, \& Cohen, 2001; Botvinick, Cohen, \& Carter, 2004), Kuhl et al. (2007) predicted that as inhibitory control managed to resolve interference across multiple retrieval practice attempts, conflict between competing memories measured by the amount of ACC activation, should be lessened. As hypothesized, the extent of the reduction in ACC activation across retrieval practices predicted the 
amount of RIF observed on the later test. Kuhl et al. further explored whether high inhibitors (as defined by the magnitude of their later behavioral RIF effect) also showed greater initial ACC activation than did low inhibitors. In other words, individuals who initially experience a high level of response conflict (i.e., retrieval competition between the target memory and other exemplars) should and did exhibit more inhibition for the competitors later on, due to the heightened amount of executive control necessary to meet the demand for response resolution. The conflict was also measurable upstream of the ACC in the medial temporal lobe where target and competitor memories were actually vying for retrieval. This ostensibly direct measure of initial conflict in the right hippocampus correlated with both ACC activity and behavioral RIF.

Thus far, we have outlined how inhibition helps overcome interference. It should be clear that lingering aftereffects of inhibition-namely reduced accessibility of competitors - though beneficial to the extent that affected memories remain contextually inappropriate, become the object of frustration when our goals change and we want to retrieve an inhibited memory at some later point. Although a number of recent investigations have demonstrated forgetting effects after periods as long as a week (Storm, Bjork, \& Bjork, 2007), an inhibited memory is not necessarily a memory lost forever. Unlike the permanent abolition of a memory trace, inhibition is often thought to be reversible, so that a memory may regain some portion of its prior accessibility as retrieval contexts demand. This may explain why others have found that the effects of RIF diminish after 24-h delays (MacLeod \& Macrae, 2001; Saunders \& MacLeod, 2002).

\section{Inhibition in memory stopping}

Not only is inhibition likely recruited in situations that demand the resolution of competition, it also plays a significant role in situations that require the cessation of actions or processes. One can easily appreciate the usefulness of inhibition on a motor level. When a baseball player is confronted with an oncoming pitch outside of the strike zone, executive control kicks in, allowing him to override the prepotent response to swing. Traditionally, motor stopping of this sort has been studied empirically using the Go/No-Go task, in which humans (de Zubicaray, Andrew, Zelaya, Williams, \& Dumanoir, 2000; Garavan, Ross, \& Stein, 1999) or monkeys (Sagkagami \& Niki, 1994; Sasaki, Gemba, \& Tsujimoto, 1989) are asked to make a physical response on a majority of trials but to withhold response when so indicated by a less-frequent stimulus. Our lab endeavored to understand whether memory retrieval can be overridden in a similar manner. Such an occasion might arise when faced with a reminder to an 
unpleasant memory or are merely in need of pushing distracting thoughts out of mind.

Drawing from the motor domain, Anderson and Green (2001) developed the Think/No-Think (TNT) paradigm that crafts a situation in which participants must intentionally exclude certain well-learned memories from awareness in the face of strong reminders. The procedure occurs in three parts, commencing with the learning phase during which participants study a series of cue-target word pairs (e.g., FLAG-SWORD; ORDEAL-ROACH; LAWN-BEEF). Following this, participants enter the critical TNT phase when they are presented with the cues of two-thirds of the learned word pairs (e.g., FLAG-; ORDEAL-). Half of these cues are presented in green, indicating that participants are to recall the associated memory as quickly as possible and keep it in mind the entire time that the cue remains on the screen (i.e., Think trials). If, however, the cue is presented in red as are the remaining half of the items, participants are instructed to avoid thinking about the associated memory (i.e., No-Think trials). In the final test phase that follows, participants are asked to recall the associated targets for all the learned cues (i.e., Think, No-Think, and Baseline cues, which do not appear in the TNT phase).

Not surprisingly, recall for those items participants practiced retrieving during the TNT phase is facilitated as a function of the number of repetitions. Of particular relevance, however, is the deficit in recall for the avoided memories in comparison to Baseline items that were learned initially but lacked reminders during the TNT phase. Again, the recallability of the targets was related to the number of times the cue was presented; yet, in this case, the relationship is inverted (Anderson \& Green, 2001; Levy \& Anderson, 2002). This finding is counterintuitive in that recurrent reminders, instead of facilitating later recall, actually served to do the opposite simply by directing subjects to push the unwanted associates out of mind. In much the same way that RIF is cue-independent, the TNT effect persists when subjects are tested with an independent probe (e.g., INSECT-R_ for ROACH), thus indicating that this impairment is not simply a result of associative interference, but is reflective of the memory itself being inhibited. If, however, the TNT paradigm's typical memorysuppression instructions are altered only slightly, such that participants are encouraged to generate an alternative target word for each No-Think cue as a means of avoiding recollection of the original target during the second phase (e.g., treating the novel word FIGHT as a target for the cue ORDEAL-), cue-independent forgetting is lost (Bergström, de Fockert, \& Richardson-Klavehn, Submitted). Given that cue independence is a critical marker of inhibition, it appears as though, in contrast to thought suppression, thought substitution is not enough to induce inhibitory forgetting. Thought substitution does appear, however, to interfere with the retrieval 
of the avoided memory when that memory is tested with the original cue from which the substitute was generated (Bergström et al., Submitted; Hertel \& Calcaterra, 2005).

To summarize, inhibiting memory retrieval bears a strong similarity to stopping a motor response on a behavioral level, at least. Does the parallel end there? An fMRI study conducted by Anderson et al. (2004) to identify the areas of the brain engaged during TNT memory suppression permitted a further comparison between the neural instantiations of the two types of stopping. Many of the so-called cognitive control regions associated with withholding motor responses, including the lateral prefrontal cortex, anterior cingulate cortex, and intraparietal sulcus (Garavan et al., 2002; Menon et al., 2001), showed evidence of increased activity during Think trials compared to No-Think trials in Anderson et al.'s (2004) study. These areas, therefore, appear to be key in inhibiting responses generally; still, the targets of the inhibitory signals are expected to diverge from the motor and premotor areas affected in the Go/No-Go task. A likely candidate in the case of memory control is the hippocampus, the region thought to support conscious recollection (Eldridge, Knowlton, Furmanski, Bookheimer, \& Engel, 2000; Squire, 1992). Substantiating this claim, Anderson et al. (2004) first reported bilateral reduction of hippocampal activity for No-Think relative to Think trials that predicted below-baseline behavioral suppression, suggesting that subjects can strategically downregulate the hippocampus to prevent conscious recollection. Depue, Curran, and Banich (2007), among others, have since replicated the hippocampal deactivation, alternatively contrasting No-Think trials with various baseline conditions.

Additionally, Depue, Banich, and Curran (2006) established that the TNT inhibition effect is not limited to verbal stimuli, replicating the belowbaseline performance in both face-word and face-place pairings. In line with the notion that thought suppression might be especially useful in inhibiting particularly distressing memories, Depue et al. (2007) found that forgetting was greatest for negatively valenced items and later showed that amygdalar activity itself is reduced over the course of No-Think trials. Forgetting highly salient (and unpleasant) memories is all the more remarkable in light of research indicating that emotional memories are more easily retrieved than nonemotional memories (e.g., Bradley, 1994; Pessoa, Kastner, \& Ungerleider, 2002). In fact, negative memories in the Think condition were facilitated in Depue et al.'s (2006) study, leading to the conclusion that the effects of executive control are malleable depending on one's goals. The desire to avoid unwanted memories is likely strongest in individuals with more extensive and intrusive thoughts, the same population that would benefit most greatly from-and have the most practice exercising - the ability to inhibit those thoughts. In support of this 
claim, Anderson and Kuhl (2004) found evidence for enhanced inhibition effects in college students with more extensive histories of trauma.

Event-related potential recordings obtained during the TNT phase offer a unique window into how people achieve memory control. Bergström, Velmans, de Fockert, and Richardson-Klavehn (2007) concluded that strategic control of memories begins at an attentional selection stage preceding conscious recollection when participants permit Think cues-but not NoThink cues-to undergo further retrieval processing. They supported this claim by pointing to an enhanced frontal positivity and posterior negativity for Think trials that occur well before the late parietal positivity denoting conscious recollection. As a further indication that participants are able to intentionally avoid thinking about unwanted memories on the level of individual items, Bergström et al. (2007) demonstrated that the ERP signature of conscious recollection observed during Think trials was practically absent during No-Think trials. These data converge with the aforementioned neuroimaging evidence offered by Anderson et al. (2004) and Depue, Curran, \& Banich (2007) demonstrating that the magnitude of forgetting for suppressed items is predicted by deactivations of the hippocampus, the brain region tied to both recollective encoding and retrieval.

Learning effectively requires focused attention, a state difficult to achieve when we are distracted by intrusive thoughts. Exerting memory control helps drive out the specter of unwanted memories while simultaneously reducing the extent to which those thoughts are likely to intrude in the future. Again, as we have seen in the case of RIF, inhibition serves to benefit learning at the expense of retention for other memories. Nevertheless, our understanding of the intricate interface between learning and forgetting remains ongoing. For example, Kawaguchi, Hotta, and Takei (2006) presented preliminary evidence that the explicit memory deficit does not extend to implicit memory tests for the targeted traces. Future investigations will help clarify the extent and duration of forgetting caused by voluntary suppression.

\section{Concluding remarks}

On one hand, learning, by definition, involves the acquisition of knowledge. Inhibition, on the other hand, involves the reduction in accessibility of a memory trace. Throughout this chapter we have presented evidence that, though seemingly at odds with each other, learning and inhibition are tightly integrated. Whether we are studying for an exam, conversing with our colleagues, or writing up a paper, we depend on executive control to retrieve the necessary facts (selective retrieval) while excluding goalirrelevant or otherwise bothersome memories from consciousness (memory 
stopping). When memories compete for retrieval or intrude, the prefrontal cortex can exert inhibitory control, thereby allowing us to accomplish our present goals. As we have seen, however, inhibition yields lasting and potentially frustrating consequences on the targets of memory control. There is still a great deal to learn about the mechanisms and consequences of inhibition; yet there is little question that a memory system that serves our goals relies upon a healthy dose of forgetting.

\section{References}

Anderson, J. R. (1974). Retrieval of propositional information from long-term memory. Cognitive Psychology, 6(4), 451-474.

Anderson, M. C. (2003). Rethinking interference theory: Executive control and the mechanisms of forgetting. Journal of Memory and Language, 49(4), 415-445.

Anderson, M. C., \& Bell, T. (2001). Forgetting our facts: The role of inhibitory processes in the loss of propositional knowledge. Journal of Experimental Psychology: General, 130, 544-570.

Anderson, M. C., Bjork, E. L., \& Bjork, R. A. (2000). Retrieval-induced forgetting: Evidence for a recall-specific mechanism. Psychonomic Bulletin and Review, 7, 522-530.

Anderson, M. C., Bjork, R. A., \& Bjork, E. L. (1994). Remembering can cause forgetting: Retrieval dynamics in long-term memory. Journal of Experimental Psychology: Learning, Memory, and Cognition, 20, 1063-1087.

Anderson, M. C., \& Green, C. (2001). Suppressing unwanted memories by executive control. Nature, 410, 131-134.

Anderson, M. C., \& Kuhl, B. (2004). Inhibitory control and the suppression of unpleasant events. Paper presented at the 45th Annual Meeting of the Psychonomic Society.

Anderson, M. C., \& McCulloch, K. C. (1999). Integration as a general boundary condition on retrieval-induced forgetting. Journal of Experimental Psychology: Learning, Memory, and Cognition, 25, 608-629.

Anderson, M. C., \& Neely, J. H. (1996). Interference And Inhibition In Memory Retrieval. In E. L. I. Bjork \& R. A. Bjork (Eds.), Memory. handbook of perception and cognition (2nd ed., pp. 237-313). San Diego: Academic Press.

Anderson, M. C., Ochsner, K. N., Cooper, J., Robertson, E., Gabrieli, S. W., Glover, G. H., et al. (2004). Neural systems underlying the suppression of unwanted memories. Science, 303, 232-235.

Anderson, M. C., \& Spellman, B. A. (1995). On the status of inhibitory mechanisms in cognition: Memory retrieval as a model case. Psychological Review, 102, 68-100.

Aslan, A., Bäuml, K. H., \& Grundgeiger, T. (2007). The role of inhibitory processes in part-list cuing. Journal of experimental psychology: Learning, Memory, and Cognition, 33(2), 335-341.

Aslan, A., Bäuml, K. H., \& Pastotter, B. (2007). No inhibitory deficit in older adults' episodic memory. Psychological Science, 18(1), 72-78. 
Barnier, A. J., Hung, L., \& Conway, M. A. (2004). Retrieval-induced forgetting of emotional and unemotional autobiographical memories. Cognition and Emotion, 18(4), 457-477.

Bäuml, K. H. (1996). Revisiting an old issue: Retroactive interference as a function of the degree of original and interpolated learning. Psychonomic Bulletin and Review, 3(3), 380-384.

Bäuml, K. H. (1997). The list-strength effect: Strength-dependent competition or suppression? Psychonomic Bulletin and Review, 4(2), 260-264.

Bäuml, K. H. (2002). Semantic generation can cause episodic forgetting. Psychological Science, 13(4), 356-360.

Bergström, Z. M., de Fockert, J., \& Richardson-Klavehn, A. (Submitted). Direct Suppression of Unwanted Memory Representations.

Bergström, Z. M., Velmans, M., de Fockert, J., \& Richardson-Klavehn, A. (2007). ERP evidence for successful voluntary avoidance of conscious recollection. Brain Research, 1151, 119-133.

Bjork, R. A. (1989). Retrieval inhibition as an adaptive mechanism in human memory. In H. L. I. Roediger and F. I. Craik (eds.), Varieties of memory and consciousness: Essays in honour of Endel Tulving (pp. 309-330). Hillsdale, NJ: Lawrence Erlbaum Associates.

Botvinick, M. M., Braver, T. S., Barch, D. M., Carter, C. S., \& Cohen, J. D. (2001). Conflict monitoring and cognitive control. Psychological Review, 108(3), 624-652.

Botvinick, M. M., Cohen, J. D., \& Carter, C. S. (2004). Conflict monitoring and anterior cingulate cortex: An update. Trends in Cognitive Sciences, 8(12), 539-546.

Bradley, M. M. (1994). Emotional memory: A dimensional analysis Hillsdale, NJ, England: Lawrence Erlbaum Associates, Inc.

Bunge, S. A., Ochsner, K. N., Desmond, J. E., Glover, G. H., \& Gabrieli, J. D. (2001). Prefrontal regions involved in keeping information in and out of mind. Brain, 124(10), 2074-2086.

Camp, G., Pecher, D., \& Schmidt, H. G. (2005). Retrieval-induced forgetting in implicit memory tests: The role of test awareness. Psychonomic Bulletin and Review, 12(3), 490-494.

Carroll, M., Campbell-Ratcliffe, J., Murnane, H., \& Perfect, T. J. (2007). Retrievalinduced forgetting in educational contexts: Monitoring, expertise, text integration and test format. European Journal of Cognitive Psychology, 19, 580-606.

Ciranni, M. A., \& Shimamura, A. P. (1999). Retrieval-induced forgetting in episodic memory. Journal of Experimental Psychology: Learning, Memory, and Cognition, 25(6), 1403-1414.

Depue, B. E., Banich, M. T., \& Curran, T. (2006). Suppression of emotional and nonemotional content in memory. Effects of repetition on cognitive control. Psychological Science, 17(5), 441-447.

Depue, B. E., Curran, T., \& Banich, M. T. (2007). Prefrontal regions orchestrate suppression of emotional memories via a two-phase process. Science, 317, 215-219. de Zubicaray, G. I., Andrew, C., Zelaya, F. O., Williams, S. C. R., \& Dumanoir, C. (2000). Motor response suppression and the prepotent tendency to respond: A parametric fMRI study. Neuropsychologia, 38, 1280-1291. 
Eldridge, L. L., Knowlton, B. J., Furmanski, C. S., Bookheimer, S. Y., \& Engel, S. A. (2000). Remembering episodes: A selective role for the hippocampus during retrieval. Nature Neuroscience, 3(11), 1149-1152.

Garavan, H., Ross, T. J., Murphy, K., Roche, R. A., \& Stein, E. A. (2002). Dissociable executive functions in the dynamic control of behavior: Inhibition, error detection, and correction. Neuroimage, 17(4), 1820-1829.

Garavan, H., Ross, T. J., \& Stein, E. A. (1999). Right hemispheric dominance of inhibitory control: An event-related functional MRI study. Proceedings of the National Academy of Sciences, 96, 8301-8306.

Gomez-Ariza, C. J., Lechuga, M., Pelegrina, S., \& Bajo, M. (2005). Retrieval-induced forgetting in recall and recognition of thematically related and unrelated sentences. Memory and Cognition, 33(8), 1431-1441.

Hertel, P. T., \& Calcaterra, G. (2005). Intentional forgetting benefits from thought substitution. Psychonomic Bulletin and Review, 12(3), 484-489.

Hulbert, J. C., \& Anderson, M. C. (In Preparation). Cue-Independent Inhibition in Retroactive Interference.

Johansson, M., Aslan, A., Bäuml, K. H., Gabel, A., \& Mecklinger, A. (2006). When remembering causes forgetting: Electrophysiological correlates of retrievalinduced forgetting. Cerebral Cortex, 17(6), 1335-1341.

Jonides, J., Smith, E. E., Marshuetz, C., Koeppe, R. A., \& Reuter-Lorenz, P. A. (1998). Inhibition in verbal working memory revealed by brain activation. Proceedings of the National Academy of Sciences, 95(14), 8410-8413.

Kawaguchi, J., Hotta, C., \& Takei, S. (2006). Implicit memory for intentionally suppressed information. Poster presented at the association for psychological science 18th annual convention, New York, NY.

Koutstaal, W., Schacter, D. L., Johnson, M. K., Angell, K. E., \& Gross, M. S. (1998). Post-event review in older and younger adults: Improving memory accessibility of complex everyday events. Psychology and Aging, 13(2), 277-296.

Koutstaal, W., Schacter, D. L., Johnson, M. K., \& Galluccio, L. (1999). Facilitation and impairment of event memory produced by photograph review. Memory and Cognition, 2\%(3), 478-493.

Kuhl, B. A., Dudukovic, N. M., Kahn, I., \& Wagner, A. D. (2007). Decreased demands on cognitive control following memory suppression reveal benefits of forgetting. Nature Neuroscience, 10, 908-914.

Levy, B. J., \& Anderson, M. C. (2002). Inhibitory processes and the control of memory retrieval. Trends in Cognitive Sciences, 6, 299-305.

Levy, B. J., McVeigh, N. D., Marful, A., \& Anderson, M. C. (2007). Inhibiting your native language: The role of retrieval-induced forgetting during second language acquisition. Psychological Science, 18(1), 29-34.

MacLeod, M. D. (2002). Retrieval-induced forgetting in eyewitness memory: Forgetting as a consequence of remembering. Applied Cognitive Psychology, 16(2), 135-149.

MacLeod, M. D., \& Macrae, C. N. (2001). Gone but not forgotten: The transient nature of retrieval-induced forgetting. Psychological Science, 12(2), 148-152.

MacLeod, M. D., \& Saunders, J. (2005). The role of inhibitory control in the production of misinformation effects. Journal of Experimental Psychology: Learning, Memory, and Cognition, 31(5), 964-979. 
Macrae, C. N., \& MacLeod, M. D. (1999a). On recollections lost: When practice makes imperfect. Journal of Personality and Social Psychology, rr(3), 463-473.

Macrae, C. N., \& MacLeod, M. D. (1999b). On recollections lost: When practice makes imperfect. Journal of Personality and Social Psychology, r7, 463-473.

McGeoch, J. A. (1942). The psychology of human learning: An introduction New York: Longmans.

Menon, V., Adleman, N., White, C., Glover, G., \& Reiss, A. (2001). Error-related brain activation during a Go/NoGo response inhibition task. Human Brain Mapping, 12(3), 131-143.

Müller, G. E., \& Pilzecker, A. (1900). Experimentalle beitrage zur lehre com gedachtnis. Zeitschrift Fur Psychologie, 1, 1-288.

Nakahara, K., Hayashi, T., Konishi, S., \& Miyashita, Y. (2002). Functional MRI of macaque monkeys performing a cognitive set-shifting task. Science, 295(5559), 1532-1536.

Pessoa, L., Kastner, S., \& Ungerleider, L. G. (2002). Attentional control of the processing of neutral and emotional stimuli. Cognitive Brain Research, 15(1), 31-45.

Postman, L. (1971). Transfer, interference and forgetting. In J. W. I. Kling \& L. A. Riggs (eds.), Woodworth and schlosberg's experimental psychology (3rd ed., pp. 1019-1132). New York: Holt, Rinehart and Winston.

Sagkagami, M., \& Niki, H. (1994). Spatial selectivity of Go/No-Go neurons in the monkey prefrontal cortex. Experimental Brain Research, 100, 165-169.

Sasaki, K., Gemba, H., \& Tsujimoto, T. (1989). Suppression of visually initiated hand movement by stimulation of the prefrontal cortex in the monkey. Brain Research, 495(1), 100-107.

Saunders, J., \& MacLeod, M. D. (2002). New evidence on the suggestibility of memory: The role of retrieval-induced forgetting in misinformation effects. Journal Of Experimental Psychology: Applied, 8(2), 127-142.

Saunders, J., \& MacLeod, M. D. (2006). Can inhibition resolve retrieval competition through the control of spreading activation? Memory and Cognition, 34(2), 307-322.

Shaw, J. S., Bjork, R. A., \& Handal, A. (1995). Retrieval-induced forgetting in an eyewitness-memory paradigm. Psychonomic Bulletin and Review, 2(2), 249-253.

Shimamura, A. P. (2000). The role of the prefrontal cortex in dynamic filtering. Psychobiology, 28(2), 207-218.

Shivde, G., \& Anderson, M. C. (2001). The role of inhibition in meaning selection: Insights from retrieval-induced forgetting. In D. I. Gorfein (ed.), On the consequences of meaning selection: Perspectives on resolving lexical ambiguity (pp. 175-190). Washington, D.C: American Psychological Association.

Smith, E. E., Adams, N., \& Schorr, D. (1978). Fact retrieval and the paradox of interference. Cognitive Psychology, 10(4), 438-464.

Squire, L. R. (1992). "Memory and the hippocampus: A synthesis from findings with rats, monkeys, and humans": Correction. Psychological Review, 99(3), 582.

Storm, B. C., Bjork, E. L., \& Bjork, R. A. (2007). When intended remembering leads to unintended forgetting. Quarterly Journal Of Experimental Psychology, 60(7), 909-915.

Thorndike, E. L. (1932). The physiological basis of the strengthening of connections by their after-effects. The fundamentals of learning (pp. 314-327). New York: NY: Teachers College Bureau of Publications. 